\title{
ANÁlisis de LAS CARACTERÍSTICAS \\ DE LA LEY I834 DE 2017 QUE FOMENTAN \\ EL SECTOR CULTURAL EN COLOMBIA
}

\author{
DAVID GÓMEZ VÁSQUEZ*, LEIDY RAMÍREZ MUÑOZ ${ }^{* *}$ \\ Y JOSÉ LUIS BERROCAL ${ }^{* * *}$
}

\section{RESUMEN}

El objetivo general del presente artículo es analizar si las características de la Ley 1834 de 2017, denominada Ley Naranja, fomentan el sector cultural en Colombia; esto comprende un recorrido a través del desarrollo, en la última década, de un modelo político-económico que pretende potencializar la cultura y fortalecer su contribución a la economía del país. Para la creación de este entorno económico se presenta una herramienta indispensable para el sector cultural y para la sostenibilidad de las organizaciones y agentes que la conforman, denominada Economía Creativa, siendo su base de negocio la transformación de los valores creativos en valores económicos. Esta tendencia ha impulsado la normatividad por la cual se busca desarrollar las industrias creativas en el país, las cuales tienen como campo de trabajo la propiedad intelectual, la creatividad y la cultura nacional.

Palabras claves: Sector cultural; Ley Naranja; industria creativa; economía naranja, cultura.

* Docente, Universidad de Antioquia. Abogado, especialista en derecho empresarial de la Universidad Católica Luís Amigó, Medellín (Colombia). Correo-e: Davidgv09@ gmail.com. Fecha de recepción: 3 de diciembre de 2020. Fecha de aceptación: 7 de febrero de 2021. Para citar el artículo: Gómez VÁsquez, David; Ramírez Muñoz, LeiDy y José Luis Berrocal. "Análisis de las características de la Ley 1834 de 2017 que fomentan el sector cultural en Colombia" en Revista de la propiedad inmaterial n. ${ }^{\circ} 31$, Universidad Externado de Colombia, enero-julio 2021, pp. 129-156. DoI: https://doi. org/10.18601/16571959.n31.05

** Abogada, especialista en derecho empresarial de la Universidad Católica Luís Amigó, Medellín (Colombia). Correo-e: Leidyramirez.m14@gmail.com.

*** Abogado, especialista en derecho empresarial de la Universidad Católica Luís Amigó, Medellín (Colombia). Correo-e: Jose.berrocalmo@amigo.edu.co. 


\section{ANALYSIS OF THE CHARACTERISTICS OF LAW I834 OF 2017}

THAT PROMOTE THE CULTURAL SECTOR IN COLOMBIA

\section{SUMMARY}

The general objective of this article is to analyze whether the characteristics of Law 1834 of 2017, called Orange Law, promote the cultural sector in Colombia, this includes a journey through the development, in the last decade, of a politicaleconomic model that aims to potentiate culture and strengthen its contribution to the country's economy. For the creation of this economic environment, an indispensable tool is presented for the cultural sector and for the sustainability of the organizations and agents that make it up, this tool was called creative economy, its business base being the transformation of creative values into economic values. This trend has promoted the regulations that seek to promote the creative industries in the country, industries whose field of work is intellectual property, creativity and national culture.

Keywords: Cultural sector; Orange Law; Creative industry; Orange Economy; Culture.

\section{INTRODUCCIÓN}

El Estado colombiano ha buscado diferentes iniciativas para resaltar la importancia de la cultura como proceso de creación de la identidad nacional, queriendo fomentar y estimular los procesos, proyectos y actividades propias del sector, adoptándola dentro del ordenamiento normativo de la Constitución Política de 1991, y pasando por diversos lineamientos y políticas que vislumbran el camino de democratización de la cultura en el país.

Fue a través de dichas iniciativas legislativas que surgió en el Congreso de la República, el 23 de mayo de 2017, la Ley 1834, denominada la Ley Naranja, en la cual se acoge el término industrias creativas, entendidas según su artículo $1 .^{\circ}$ como aquellas industrias que generan valor en razón de sus bienes y servicios fundamentados en la propiedad intelectual. Esos bienes y servicios se basan en un contenido de carácter cultural que, según la norma, se puede desarrollar en un modelo denominado Economía Naranja.

Como lo manifiestan Duque y Buitrago ${ }^{1}$ este modelo se presenta como una herramienta indispensable para el sector cultural que busca definir la Economía Naranja, entender que es una oportunidad importante, y que se debe apreciar la dimensión de su contribución a la economía. Para estos autores, la economía y la 
cultura se relacionan directamente, lo que ayuda a crear un entorno económico en el que se requiere la implementación de siete estrategias, denominadas "las 7i", que surgen para responder a las varias falencias del sector cultural: información, instituciones, industria, infraestructura, integración, inclusión e inspiración, que si bien pueden parecer una colección de consejos de sentido común, para Duque y Buitrago, lo importante era comenzar por establecer lo que es obvio y en constantes ocasiones olvidado, apropiándose además del concepto "mentefacturas" en el que se son necesarias "mentes más creativas, las mejores ideas y los visionarios más osados" ${ }^{2}$ que permitan crear, producir, distribuir y comercializar contenidos artísticos y culturales.

En ese sentir, la Economía Naranja se presenta en Colombia como la gran apuesta por la cultura; pero esta ley no diferencia entre sector cultural, empresa e industria creativa, delimitación necesaria de mercado que termina generando contraposiciones en los discursos teóricos de los estudios culturales y que podría imposibilitar que efectivamente se trabaje sobre las necesidades propias del sector. De esa manera lo manifiesta Germán Benjumea:

El problema puede surgir cuando Puerto Candelaria, la Filarmónica de Medellín, el Ateneo Porfirio Barba Jacob, el Teatro Pablo Tobón Uribe, el Centro de Desarrollo Cultural de Moravia, entre otras miles de propuestas están protegidas con la normatividad pensada para Netflix, Claro, Planeta, RCN, Conmebol, las ferias internacionales, Maluma, JBalvin, Osesa, la industria fonográfica y Google, pues las primeras requieren una legislación más específica para empresas culturales no lucrativas y no para la industria cultural y del entretenimiento 3 .

Es aquí donde se encuentra el objetivo de este trabajo, en el cual se analiza si las características de la Ley 1834 de 2017 fomentan el sector cultural en Colombia. Para ello se estudia en el primer capítulo una delimitación del sector cultural en el que se abordan los términos que referencian las actividades, procesos y proyectos propios del sector, a su vez que se hace un rastreo de los antecedentes normativos encargados de su regulación y fomento.

En un segundo capítulo se estudia la Ley 1834 de 2017, lo que permite conocer qué ofrece la normatividad que desarrolla la Economía Naranja en cuanto a las características y objetivos que buscan ser ejecutados en el sector cultural.

En un tercer y último capítulo se plasma la relación entre el sector cultural y la Ley Naranja, a través de un análisis comparativo entre la Ley 1834 de 2017 y las necesidades que manifiestan los sujetos u órganos que integran el sector. Para luego concluir si existe un efectivo fomento del sector cultural en Colombia.

2 Ibíd., pp. 155.

3 Benjumea, Germán. “Economía cultural en Medellín”, Diverciudad, n.o 23, 2018 , p. 27 . 


\section{CAPÍTULO I. EL SECTOR CULTURAL EN COLOMBIA}

La expedición de la Constitución Política de Colombia de 1991 que estructura el ordenamiento jurídico de la nación, trajo consigo valiosos avances respecto a los derechos culturales y, en especial, al fomento del sector cultural, evidenciándose en su regulación la concepción de cultura como valor, principio y bien merecedor de especial protección y reconocimiento por parte del Estado.

Su normatividad más diciente en cuanto al fomento del sector cultural es el artículo 70, el cual rescata la importancia de la cultura para los colombianos, y cómo esta influye en el proceso de creación de la identidad nacional, a la vez que establece algunos principios propios de la cultura: igualdad, dignidad y calidad.

El Estado tiene el deber de promover y fomentar el acceso a la cultura de todos los colombianos en igualdad de oportunidades por medio de la educación permanente y la enseñanza científica, técnica, artística y profesional en todas las etapas del proceso de creación de la identidad nacional. La cultura en sus diversas manifestaciones es fundamento de la nacionalidad. El Estado reconoce la igualdad y dignidad de todas las que conviven en el país. El Estado promoverá la investigación, la ciencia, el desarrollo y la difusión de los valores culturales de la nación ${ }^{4}$.

Otra normatividad de la Constitución Política de Colombia que reconoce el sector cultural es el artículo 71, el cual cita:

La búsqueda del conocimiento y la expresión artística son libres. Los planes de desarrollo económico y social incluirán el fomento a las ciencias y, en general, a la cultura. El Estado creará incentivos para personas e instituciones que desarrollen y fomenten la ciencia y la tecnología y las demás manifestaciones culturales, y ofrecerá estímulos especiales a personas e instituciones que ejerzan estas actividades ${ }^{5}$.

Producto de los lineamientos normativos de la Constitución Política de 1991 y del interés de los dirigentes estatales de turno por resaltar la importancia de la diversidad cultural de Colombia, en 1997 se promulgó la Ley 397, llamada Ley General de Cultura, la cual desarrolló los artículos 70, 71 y 72 de la Constitución Política, cuyo principal objetivo era asignar una definición para la cultura, estableciéndola como el "conjunto de rasgos distintivos, espirituales, materiales, intelectuales y emocionales que caracterizan a los grupos humanos, y que comprende más allá de las artes y las letras, modos de vida, derechos humanos, sistemas de valores, tradiciones y creencias" ${ }^{\prime \prime}$. Además, se encargó de definir el patrimonio cultural,

4 Constitución Política de Colombia 1991, artículo 70, Gaceta Constitucional n.o 116 de 20 de julio de 1991.

5 Ibíd., artículo 71.

6 Congreso de la República. "Ley 397. Por la cual se desarrollan los artículos 70, 71 y 72 y demás artículos concordantes de la Constitución Política y se dictan normas 
estableciendo los mecanismos para su declaración y registro, y también instauró la reglamentación y las sanciones frente a su uso y conservación. Igualmente, se encargó del fomento y los estímulos a la creación artística, a la investigación y a las instituciones culturales, los mecanismos de financiación de la actividad cultural, la profesionalización del artista, la seguridad social y su relación con los derechos de autor.

La Ley General de Cultura es el producto de la sistematización de los derechos y deberes relacionados con la diversidad, la participación y las prácticas culturales que conforman el sector, el cual el Estado busca fomentar y proteger.

Pero, ¿qué es el sector cultural?

Al hablar del sector cultural, Arroyo ${ }^{7}$ se refiere inmediatamente al sector de servicios, es decir, a la acción propia de las personas, expresión que no se puede separar de conceptos como bienes culturales, objetos culturales, mercados de la cultura e, incluso, de industria creativa.

Frente a ello, Germán Benjumea ${ }^{8}$ hace una delimitación necesaria de mercado, toda vez que no hay distinción en los términos que se mezclan en el discurso de la industria creativa. La primera área de mercado a la que se refiere es la actividad artística o sector cultural, la cual abarca propiamente el arte y sus variantes: artes plásticas, artes escénicas, música, teatros, museos, compañías. La segunda es la industria cultural, área de mercado que abarca los imperios masivos del entretenimiento como el cine, la televisión, la prensa y las editoriales. En un tercer momento habla de las industrias creativas, que por su funcionalidad y características hacen parte de las empresas dedicadas a lo utilitario y funcional como el diseño, la arquitectura o la publicidad, entre otros. Por último, se refiere a las industrias relacionadas con la cultura y la creatividad, pero que no desarrollan una actividad de las bellas artes, como la gastronomía, la moda, el deporte, el turismo, la multimedia y las noticias.

Sin embargo, definir el sector cultural puede ser una tarea compleja; en ese sentido, Luis Fernando Aguado9 manifiesta que existe una confusa controversia respecto de las delimitaciones del sector cultural, lo cual genera contraposiciones en los discursos teóricos y académicos de los estudios culturales respecto de la definición, los límites y el campo de acción de la cultura y la industria creativa que, a su vez, repercuten en el valor de la cultura.

$\mathrm{Al}$ identificar las necesidades de la gestión cultural, el Observatorio Cultural del Proyecto Atalaya decidió trabajar en un manual básico de introducción que

sobre patrimonio cultural, fomentos y estímulos a la cultura, se crea el Ministerio de la Cultura y se trasladan algunas dependencias", artículo $1 .^{\circ}$, Diario Oficial n. ${ }^{\circ} 43102$, del 7 de agosto de 1997.

7 Arroyo, Luís Miguel. "Sectores de la cultura", Observatorio Cultural del Proyecto Atalaya, Manual Atalaya, apoyo a la gestión cultural, 2014. Disponible en [http://atalayagestioncultural.es/capitulo/sectores-cultura].

8 Benjumea. Op. cit., pp. 23-24.

9 Aguado, Luís Fernando. Configuración y delimitación de la economía de la cultura: elementos históricos, analíticos y metodológicos, Universidad de Sevilla, 2010, p. 123. 
fije las bases de la profesión, denominado Manual Atalaya de apoyo a la gestión cultural, en el cual se define el sector cultural como:

... la actividad propiamente dicha y a los sujetos que las desarrollan (las llamadas empresas e industrias culturales) o que las disfrutan (los consumidores, sea individualmente o en forma de público), a los actores públicos que intervienen sobre las mismas (Administraciones, legisladores, entes públicos diversos, etc.) y a la problemática que suscita cada uno de los mercados específicos sobre los que se asientan las actividades culturales que se desarrollan y los bienes culturales que se encuentran afectados ${ }^{10}$.

Luis Miguel Arroyo ${ }^{11}$ determina las actividades propias del sector cultural en artes escénicas, artes plásticas, artes audiovisuales y multimedia, patrimonio, archivos y bibliotecas, libros y prensa, y música e industria fonográfica.

A su vez, el Compendio de politicas culturales del Ministerio de Cultura ${ }^{12}$ establece que, entre otras, las políticas culturales se construyen con una amplia base social, reconocen la diversidad de las manifestaciones artísticas, sus procesos de formación y sus procesos de creación, y a su vez conforman el sector cultural, esto es: las artes, las artes visuales, la música, la literatura, el teatro, la danza y el cine.

\section{ANTECEDENTES NORMATIVOS DEL SECTOR CULTURAL EN COLOMBIA}

A partir de la Constitución de 1991 el aparato normativo relacionado con la cultura comenzó a reforzar la institucionalidad cultural con el fin de proteger, reconocer y rediseñar sus campos, y a su vez, se fortalecieron los medios de comunicación, aumentando la interacción de la cultura con otras áreas de la gestión pública y la sociedad, y se insertó el sector cultural en el escenario económico, político y social a nivel nacional e internacional ${ }^{13}$, donde las políticas culturales tomaron una gran importancia para el desarrollo legislativo.

Ochoa Gautier define la política cultural como

... la movilización de la cultura llevada a cabo por diferentes tipos de agentes -el Estado, los movimientos sociales, las industrias culturales, instituciones tales como museos u organizaciones turísticas, asociaciones de artistas y otros- con fines de transformación estética, organizacional, política, económica y/o social ${ }^{14}$.

10 Arroyo. Op. cit.

11 Ibíd.

12 Ministerio de Cultura. "Compendio de Políticas Culturales, 2010". Disponible en [https://www.mincultura.gov.co/areas/fomento-regional/Documents/CompendioPol\%C3\%ADticas-Culturales.pdf].

13 Rey, Germán. "Las políticas culturales en Colombia: la progresiva transformación de sus comprensiones", Ministerio de Cultura de Colombia. "Compendio de Políticas Culturales", 2010, p. 23. Disponible en [https://www.mincultura.gov.co/areas/fomentoregional/Documents/Compendio-Pol\%C3\%ADticas-Culturales.pdf].

14 Ochoa Gautier, Ana María. Entre los deseos y los derechos: un ensayo crítico sobre 
Por ende, tras analizar el Compendio de politicas culturales y el Compendio de legislación cultural $^{15}$, ambos del Ministerio de Cultura y desarrollados en el año 2010, se puede evidenciar la normatividad propia del sector cultural en Colombia.

A continuación, se presenta una tabla donde se relacionan las leyes principales que fomentan dicho sector.

Tabla i. Principales leyes que fomentan el sector cultural en Colombia

\begin{tabular}{|l|l|}
\hline \multicolumn{1}{|c|}{ LeY } & \multicolumn{1}{|c|}{ DESCRIPCión } \\
\hline $\begin{array}{l}\text { Ley } 23 \text { de } 1982 \\
\text { Ley de Derechos de Autor }\end{array}$ & $\begin{array}{l}\text { Regula los derechos de autor y derechos conexos, y los actos y } \\
\text { documentos que se refieren a ellos. }\end{array}$ \\
\hline $\begin{array}{l}\text { Ley } 98 \text { de } 1993 \\
\text { Democratización del Libro Co- } \\
\text { lombiano }\end{array}$ & $\begin{array}{l}\text { Busca la plena democratización del libro y su uso más amplio } \\
\text { como medio de difusión de la cultura, la transmisión del cono- } \\
\text { cimiento, el fomento de la investigación social y científica, la } \\
\text { conservación del patrimonio de la Nación, y el mejoramiento } \\
\text { de la calidad de vida de todos los colombianos. }\end{array}$ \\
\hline $\begin{array}{l}\text { Ley } 182 \text { de } 1995 \\
\text { Reglamenta el servicio de televi- } \\
\text { sión y se formulan políticas para } \\
\text { su desarrollo }\end{array}$ & $\begin{array}{l}\text { Fomentar el desarrollo del servicio de televisión, democratizar } \\
\text { el acceso a este servicio, promover la industria televisiva y } \\
\text { actividades afines. }\end{array}$ \\
\hline $\begin{array}{l}\text { Ley } 814 \text { de } 2003 \\
\text { Fomento de la actividad cinema- } \\
\text { tográfica en Colombia }\end{array}$ & $\begin{array}{l}\text { Propiciar un desarrollo progresivo, armónico y equitativo de } \\
\text { la cinematografía nacional y, en general, promover la actividad } \\
\text { cinematográfica en Colombia. }\end{array}$ \\
\hline $\begin{array}{l}\text { Ley } 1170 \text { de } 2007 \\
\text { Ley de Teatro Colombiano }\end{array}$ & $\begin{array}{l}\text { Considera la actividad teatral o escénica a toda representación } \\
\text { de un hecho dramático o cómico, manifestado artísticamente } \\
\text { a través de distintos géneros creativos. La actividad teatral y } \\
\text { escénica, por su contribución al afianzamiento de la cultura } \\
\text { nacional, será objeto de la promoción y apoyo del Estado } \\
\text { colombiano. }\end{array}$ \\
\hline $\begin{array}{l}\text { Ley } 1379 \text { de } 2010 \\
\text { Fomento del Libro }\end{array}$ & $\begin{array}{l}\text { A través de esta ley se organiza la Red Nacional de Bibliotecas } \\
\text { Públicas, la cual tiene por objeto definir su política, regular su } \\
\text { funcionamiento y establecer los instrumentos para su desarrollo } \\
\text { integral y sostenible. }\end{array}$ \\
\hline $\begin{array}{l}\text { Ley } 1558 \text { de } 2012 \\
\text { Ley del Turismo }\end{array}$ & $\begin{array}{l}\text { Fomentar y reglamentar las artes escénicas y preservar el patri- } \\
\text { monio cultural del país. }\end{array}$ \\
\hline & $\begin{array}{l}\text { El fomento, el desarrollo, la promoción, la competitividad del } \\
\text { sector turístico. }\end{array}$ \\
\hline
\end{tabular}

A continuación, se relacionan los principales decretos que acompañan el fomento del sector cultural en el país.

politicas culturales, Bogotá, Instituto Colombiano de Antropología e Historia (ICANH), 2003, p. 20.

15 Ministerio de Cultura. Op. cit. 
Tabla 2. Decretos QUe acompañan El Fomento del Sector CUltural

\begin{tabular}{|l|l|}
\hline \multicolumn{1}{|c|}{ DECRETO } & \multicolumn{1}{c|}{ DESCRIPCIón } \\
\hline Decreto ley 1903 de 1990 & $\begin{array}{l}\text { Regula la actividad cinematográfica teniendo en cuenta la contri- } \\
\text { bución del cine al desarrollo social, económico y cultural del país. }\end{array}$ \\
\hline Decreto 1493 de 1998 & $\begin{array}{l}\text { Reglamenta la participación del Ministerio de Cultura en la creación } \\
\text { de los fondos mixtos para la promoción de la cultura y las artes de- } \\
\text { partamentales, distritales, municipales y de los territorios indígenas. }\end{array}$ \\
\hline Decreto 1589 de 1998 & $\begin{array}{l}\text { Reglamenta el Sistema Nacional de Cultura (sNCu), definido como } \\
\text { el conjunto de instancias, espacios de participación y procesos de } \\
\text { desarrollo institucional, planificación, financiación, formación, e } \\
\text { información articulados entre sí, que posibilitan el desarrollo cultural } \\
\text { y el acceso de la comunidad a los bienes y servicios culturales. }\end{array}$ \\
\hline Decreto 1080 de 2015 & $\begin{array}{l}\text { Decreto Unico Reglamentario del Sector Cultura cuyo objeto es com- } \\
\text { pilar y racionalizar las normas de carácter reglamentario expedidas por } \\
\text { el Gobierno Nacional para la cumplida ejecución de las leyes del sector } \\
\text { cultura y para contar con un instrumento jurídico único para el mismo }\end{array}$ \\
\hline
\end{tabular}

\section{CAPÍTULO 2. SOBRE LA LEY I834 DE 2017}

En 1998 se realizó en Estocolmo la Conferencia Intergubernamental sobre Políticas Culturales para el Desarrollo, en la cual se expuso la relación entre el desarrollo y la cultura, donde la creatividad representa la fuente del progreso humano y la diversidad cultural. La conferencia estableció como premisas que: 1. La política de desarrollo debe ser endógena y duradera, y 2. Las políticas para el desarrollo deben ser sensibles a la cultura. De este modo la cultura deja de ser un factor humano que cumple funciones simplemente sociales para convertirse en una finalidad de desarrollo, apostando identidad, diversidad e interculturalidad ${ }^{16}$.

La relación entre cultura y desarrollo económico se puede observar a partir de dos aspectos: i) las actividades culturales que provocan efectos a corto y largo plazo en el crecimiento de la economía, y ii) el crecimiento económico que incide en la transformación del sector cultural, este último en el entendido de su estructura productiva, la demanda de bienes y servicios culturales, el desarrollo tecnológico, la acumulación de capital y los nuevos alcances de las políticas culturales ${ }^{17}$. A esta relación entre cultura y economía se le denominó Economía Creativa, término popularizado por John Howkins ${ }^{18}$ el cual hace referencia a los modelos de negocios relacionados con las industrias culturales, creativas y de generación de ideas. Dicho

16 Rey, Germán. Industrias culturales, creatividad y desarrollo, Madrid, Agencia Española de Cooperación Internacional para el Desarrollo, s.f., pp. 12-17

17 Herrero, Luis. "La contribución de la cultura y las artes al desarrollo económico regional”, Investigaciones Regionales, 2011, p. 198.

18 Hownins, John. "The Creative Economy: How People Make Money from Ideas", UK, Penguin, 2001, p. 8. Disponible en [https://bookports.com/show/the-creativeeconomy-how-people-make-money-from-.html]. 
concepto surgió a partir de la convergencia de los bienes y servicios creativos y artísticos llevados al mercado.

En consecuencia, de la mano de las instituciones culturales, los gobiernos comenzaron a resaltar la importancia de la cultura en la economía, definiendo políticas culturales encaminadas a la industrialización, el crecimiento de la producción nacional y el apoyo a los creadores locales, proyectando el fomento de las pequeñas y medianas empresas culturales, creando fondos públicos y privados de financiación, permitiendo el acceso al disfrute de la cultura y el apoyo a sistemas eficientes de distribución de bienes y servicios culturales. Lo anterior se refleja en las leyes que expiden los gobiernos, los tratados de libre comercio que suscriben, y las demás obligaciones estatales en las que se rescata la cultura y sus manifestaciones tales como "las cuotas de pantalla de cine y televisión, la neutralidad tecnológica, los sistemas de derecho de autor, las responsabilidades de quienes prestan servicios de Internet o los programas de beneficios a la creación"19.

En Colombia la economía de bienes y servicios culturales representa para el Estado una productividad del 3.5 al 4\% del Producto Interno Bruto (PIB), y cuenta con aproximadamente 8.333 empresas distribuidas principalmente en danza, moda, cine, gastronomía típica y tecnología. El impacto de esta economía es tan positivo que, según reportes de la Cámara de Comercio de Bogotá, en 2015 el desarrollo empresarial cultural generó más de 290.000 empleos formales, y a su vez la exportación de bienes y servicios creativos creció en un 134\%, entendidos estos bienes como: artes visuales y performativas, artesanía, audiovisual, diseño, nuevos medios, arquitectura, cultura y recreación, investigación y desarrollo, y publicidad ${ }^{20}$.

A partir de ese momento la cultura y la creatividad se instalaron como potenciales motores de crecimiento y desarrollo con los que se pretende expandir las industrias culturales y creativas pensadas en la Cuarta Revolución Industrial; se trata de una revolución digital que potencia la economía y resalta la posición y visión del sector cultural que hasta ese momento no era considerado a la hora de pensar en políticas de desarrollo. Cambió, entonces, la forma como se percibe su valor, y se pasó de considerarlo solo como un bien público a apreciarlo como un motor de desarrollo económico, el cual cuenta con reservas ilimitadas de talento y creatividad que concuerdan con los cambios experimentados por la economía mundial, pasando de ser un prototipo basado en las manufacturas a una economía del conocimiento y la información, en donde la cultura desempeña un papel crucial.

Y es que la cultura tiene un gran impacto en la economía a través de sus diversas expresiones, producto de la creación, que abarcan desde las industrias creativas hasta las nuevas tecnologías, las cuales, de la mano de la creciente conectividad, han fortalecido el comercio de bienes y servicios culturales en un $70 \%$.

Todo lo anterior validó la necesidad de contar con una ley que fomentara la economía creativa, y, en consecuencia, surgió la Ley 1834 de 2017, Ley Naranja,

19 Rey. Op. cit., p. 42.

20 Quintana, Boris. El color naranja del diseño, Ceide, 2018, pp. 6 y 19. 
promovida por Iván Duque y Felipe Buitrago ${ }^{21}$, con la finalidad de resaltar la importancia del modelo de economía creativa y su peso en el marco de los derechos de la propiedad intelectual, los cuales no habían sido analizados desde la perspectiva de su impacto económico y las oportunidades que abarcan. Esta revalorización de las manifestaciones culturales implicaba para la política pública concordar derechos humanos, fundamentales y colectivos respecto de la creación, la expresión, el acceso y el consumo culturales.

En 2013 Felipe Buitrago e Iván Duque pretendieron generar una discusión respecto de la economía creativa, la cual, señalaron, traería consigo inmensas oportunidades de desarrollo al poderse cuantificar los bienes y servicios culturales en términos monetarios, y definieron el modelo como un

... conjunto de actividades que de manera encadenada permiten que las ideas se transformen en bienes y servicios culturales, cuyo valor está determinado por su contenido de propiedad intelectual. El universo naranja está compuesto por: la economía cultural y las industrias creativas, en cuya intersección se encuentran las industrias culturales convencionales; y las áreas de soporte para la creatividad ${ }^{22}$.

La estrategia de pensar en una economía creativa se estableció como una nueva oportunidad para impulsar la producción de bienes y servicios con generación de valor económico para productores y consumidores; dicha estrategia busca explotar una fuente abundante de recursos con que cuenta nuestro país: su creatividad y su cultura, recursos que permitirían enfrentar con mayores posibilidades las nuevas maneras de producir.

\section{APUNTES SOBRE LA ECONOMÍA NARANJA}

La entidad precursora en las investigaciones económicas sobre las industrias creativas en América Latina y el Caribe es el Banco Interamericano de Desarrollo (BID); de sus investigaciones se resalta el impacto que puede tener el desarrollo de la Economía Naranja en la innovación y en la promoción de nuevas tecnologías, al igual que su importancia para dar apoyo a los emprendedores y a las industrias creativas, de las cuales se busca una formalización laboral y la creación de nuevos empleos con garantía de permanencia en la economía del país ${ }^{23}$.

De igual manera, Escobar, Forero y Vargas ${ }^{24}$ consideran la Economía Naranja como una oportunidad que ofrece un desarrollo alternativo a los modelos tradi-

21 Duque y Buitrago. Op. cit., pp. 28-30.

22 Ibíd., pp. 40.

23 Contraloría General de la Nación. Economía colombiana. Revista de la Contraloría General de la República, año 33. n..$^{\circ} 354$, s.f., p. 7.

24 Escobar, Gabriela, Forero, Tatiana y Vargas, Paula. "La institucionalidad de la economía naranja en Colombia: un estudio neo-institucional para el periodo 2010-2014", 2017, p. 21. Disponible en [https://ciencia.lasalle.edu.co/negocios_relaciones/43]. 
cionales de negocio basados en la tierra o el capital, y se presenta como un sector realmente capaz de producir crecimiento, entendiendo que esta economía, además de generar impacto social crea riqueza económica. Así lo demuestra el impacto económico de la economía creativa en el PIB, que Duque y Buitrago ${ }^{25}$ clasifican como un contribuyente neto. Las exportaciones de bienes y servicios creativos en 2011 alcanzaron los USD 646.000 millones, lo cual significa que fue la quinta mercancía más transada del planeta, por encima de sectores tradicionales como la agricultura o la minería, al crecer 134\% entre 2002 y 2011. Particularmente América es una región altamente competitiva en la Economía Naranja global debido a la participación de EEUU que en 2011 exportó USD 87.6 mil millones, con una participación del $13.5 \%$. Además, el comercio derivado de la economía creativa ha demostrado ser menos volátil, soportando mejor la crisis financiera global que, por ejemplo, el sector petrolero en el que los precios internacionales de crudo presentan serias fluctuaciones.

Otra importancia de la Economía Naranja radica en la conectividad, ya que el comercio de servicios creativos crece más rápido a través de Internet en la era de las tecnologías de la información y de los desarrollos tecnológicos y científicos, así como del Internet móvil, el trabajo de conocimiento y el Internet de las cosas, entre muchas otras herramientas que evidencian que "con la crisis y el agotamiento de los modelos de negocio y de consumo clásico, los soportes y redes digitales van generando nuevos tipos de ofertas y de consumo cultural" ${ }^{26}$, por lo que al fortalecer un modelo de Economía Naranja se diversificaría la contribución al crecimiento, transformando lo mejor del talento creativo y de las enormes reservas de patrimonio cultural del país con la posibilidad de hacer más resistente la economía frente a futuras crisis, por ser los bienes y servicios culturales altamente renovables ${ }^{27}$.

De la misma manera Gutiérrez ${ }^{28}$ comprende el desarrollo económico como fundamento de la Ley Naranja, cuando manifiesta que la idea de la Economía Naranja es que desde la política local, regional y nacional se promueva la creación de empresas, apoyadas por instituciones como Bancóldex, iNNpulsa Colombia y el Fondo Emprender. Considera que de alguna manera se busca ayudar a impulsar el emprendimiento y generar un impacto positivo en el desarrollo del país.

\section{CARACTERÍSTICAS DE LA LEY I834 DE 2017}

La Ley 1834 de 2017, también denominada Ley Naranja, determina los parámetros generales a los que se deben acoger el gobierno, las instituciones públicas,

25 Duque y Buitrago. Op. cit., pp. 17-18.

26 Álvarez, Miguel Ángel. Industrias creativas y culturales y la economía de la imaginación, Ábaco, 2010, p. 28.

27 UnCTAD. Economía Creativa Informe 2010. “Economía creativa: una opción factible de desarrollo", Naciones Unidas, 2010, p. 14.

28 Gutiérrez, Diana. Economía Naranja y oportunidades de negocio, Fundación Universitaria del Área Andina, 2018, p. 12. 
los agentes culturales y del sector privado para liderar el cambio hacia un nuevo modelo económico y social en el que la cultura esté en el centro del desarrollo de la Política para una Economía Naranja. Con la expedición de esta ley el gobierno colombiano busca "desarrollar, fomentar, incentivar y proteger las industrias creativas" entendidas como aquellas "que generan valor en razón de sus bienes y servicios, los cuales se fundamentan en la propiedad intelectual" 29 .

Milagros del Corral $^{30}$ considera que las industrias creativas son esenciales para promover la diversidad cultural, toda vez que aportan un valor añadido a los contenidos culturales, siendo su base de negocio la transformación de los valores simbólicos de la cultura en valores económicos. De este modo, expresa la autora, se democratiza el acceso a la cultura.

En consecuencia, y teniendo en cuenta el impacto y desarrollo económico de las industrias creativas, el artículo $2 .^{\circ}$ de la Ley Naranja las define como aquellas que en su objeto consagran la creación, producción y/o comercialización de bienes y servicios culturales, tangibles o intangibles, protegidos por los derechos de autor. De forma genérica, la definición abarca diversos sectores de la cultura: editorial, audiovisual, fonográfico, de artes visuales, escénicas y espectáculos, de turismo y patrimonio cultural material e inmaterial, educación artística y cultural, diseño, publicidad, contenidos multimedia, software, moda, agencias de noticias y servicios de información, y educación creativa ${ }^{31}$.

Dicha definición se acopla a las definiciones internacionales sobre industrias creativas, las cuales tienen en común la creatividad, las artes y la cultura como materia prima. De este modo se puede presentar una cadena de valor creativa, donde a las industrias de este sector económico se les denomina "industrias culturales, las industrias creativas, las industrias del ocio, las industrias del entretenimiento, las industrias de contenidos, las industrias protegidas por el derecho de autor, la economía cultural y la economía creativa" 32 .

De ese modo, para el efectivo desarrollo de la Economía Naranja en el país, el legislador determinó la obligación del Estado de crear la Política Integral de la Economía Creativa o también llamada Política Naranja, comprendida como una estrategia a través de la cual el gobierno coordina y articula lineamientos encaminados al fomento y mejora de los sectores culturales dentro de la economía nacional. Es por esa razón que para implementar la Ley 1834 de $2017^{[33]}$ se establecieron

29 Congreso de la República de Colombia. Ley 1834. "Por medio de la cual se fomenta la economía creativa Ley Naranja, artículo 1. ${ }^{\circ}$, Diario Oficial n. ${ }^{\circ} 50.242$ del 23 de mayo de 2017.

30 Del Corral, Milagros. "Hacia nuevas políticas de desarrollo de las industrias culturales", Anuario Industrias Culturales, Observatorio de Industrias Culturales de la Ciudad de Buenos Aires, 2006, p. 3. Disponible en [http://www.ub.edu/cultural/wpcontent/uploads/2019/12/1-1_1316768187_bgc13-MCorral.pdf].

31 Congreso de la República de Colombia. Ley 1834, artículo 2..

32 Duque, Iván. "Proyecto de Ley 104 de 2015, Exposición de motivos, 2015, p. 10. Disponible en [http://leyes.senado.gov.co/proyectos/index.php/textos-radicados-senado/26textos-radicados/pl-radicados-2015-2016/533-proyecto-de-ley-104-de-2015].

33 Congreso de la República de Colombia. Ley 1834, artículo 5.. 
inicialmente siete estrategias que se denominaron las $7 \mathrm{i}$, incorporadas en su artículo $5 .^{\circ}$ y desarrolladas en los artículos siguientes, las cuales constituyen la ruta de acción del Gobierno Nacional para consolidar el sector cultural, a través de la implementación de la información, las instituciones, la industria, la infraestructura, la integración, la inclusión y la inspiración.

La primera estrategia que permite relacionar la cultura con la economía es la información, a través de la cual es posible involucrar a los profesionales y expertos en temas de economía y análisis de mercado con el fin de que, a partir de sus experiencias, se mejoren las prácticas de las industrias creativas, y se generen mayores y mejores oportunidades ${ }^{34}$.

En la exposición de motivos de la Ley 1834 Duque $^{35}$ señala que en esta primera estrategia se requieren expertos que ayuden a cerrar la brecha social mediante el análisis y la construcción de políticas culturales; a su vez, es necesario que los agentes culturales se informen sobre los alcances y la importancia económica del sector.

Para esta primera estrategia, el artículo 6. ${ }^{\circ}$ de la Ley Naranja implementa en el territorio nacional la Cuenta Satélite del Sector Cultural, encabezada por el Departamento Administrativo Nacional de Estadística (DANE) en coordinación con el Ministerio de Cultura, con la finalidad de establecer los diagnósticos y mediciones económicas de las industrias creativas ${ }^{36}$. La cuenta satélite tiene por objeto, entre otros, generar un sistema de información continua que permita visibilizar las actividades económicas culturales del país, comparando su evolución en diferentes períodos de tiempo, y brindar información idónea para que las organizaciones y entidades encargadas de las políticas culturales puedan tomar decisiones en beneficio del sector ${ }^{37}$.

A finales del siglo xx los países empezaron a crear sus ministerios de cultura para promover iniciativas que regulen el desarrollo artístico y el acceso a bienes y servicios culturales. En este sentido, la segunda estrategia de la $7 \mathrm{i}$ son las Instituciones, "como mecanismos de cooperación y coordinación para el progreso de la Economía Naranja”38. Esta estrategia busca coordinar el sector público con el privado, el mixto y el no gubernamental, integrando a las diferentes ONG culturales a los procesos de agregación de valor, y así aumentar el progreso de la Economía Naranja ${ }^{39}$.

El artículo 7. de la Ley Naranja creó el Consejo Nacional de la Economía Naranja (CNEN), el cual funge como coordinador institucional y cuenta con la participación de doce instituciones públicas directamente relacionadas con la industria

34 Duque y Buitrago. Op. cit., pp. 161-165.

35 Duque, Iván. Op. cit., p. 18.

36 Congreso de la República de Colombia. Ley 1834, artículo 6.․

37 Ministerio de Cultura. "Impacto económico de las industrias culturales en Colombia”, Equipo Central de Economía y Cultura del Convenio Andrés Bello, Colección Economía y Cultura, 2003, p. 196.

38 Duque, Iván. Op. cit., p. 18.

39 Duque y Buitrago. Op. cit., pp. 166-168. 
creativa, mencionadas en el mismo artículo. A su vez, delega en el Ministerio de Cultura, como órgano asesor y consultivo del Gobierno Nacional, la creación de los lineamientos y las acciones interinstitucionales necesarias para la promoción, defensa, divulgación y desarrollo de la política de Economía Naranja ${ }^{40}$.

La tercera estrategia, denominada Industria, se enfoca en la necesidad de contar con personas creativas que aporten a la economía nacional buenas y mejores ideas. Sin embargo, se debe reconocer, como señala Duque ${ }^{41}$ en la exposición de motivos, que muchos de los actores dentro del sector cultural no buscan un enriquecimiento por su quehacer creativo, lo que implica, entonces, que el Estado debe aclarar las necesidades del sector dentro de la economía, para eliminar la desconfianza de los agentes culturales frente a los demás agentes que coadyuvan dentro del sector, como los mánagers, los abogados, las comercializadoras, las editoriales y los inversionistas. Lo anterior implica que las industrias creativas deben mantener diálogos constantes con los agentes culturales para que estos integren a los procesos económicos ideas, contenidos, bienes y servicios alrededor de un proyecto económicamente sostenible ${ }^{42}$.

Además, se establece que para sostener la Economía Naranja y las industrias creativas en el país el Estado debe permitir la

... importación y exportación de bienes y servicios vinculados a actividades creativas y culturales, facilitación migratoria, promoción de agremiaciones dentro del sector, administración adecuada de las sociedades de gestión colectiva y el establecimiento de incentivos estratégicos sectoriales, entre otras acciones ${ }^{43}$.

Para la Economía Naranja es clave facilitar el contacto entre la industria creativa y las audiencias, los contenidos, los artistas, los agentes creativos, los emprendedores, y las tecnologías, permitiendo de ese modo potenciar la capacidad de intercambio cultural acompañado de los medios digitales ${ }^{44}$. Lo anterior se pensó para la cuarta estrategia que se refiere a la necesidad de crear infraestructuras tanto físicas como virtuales que faciliten un acceso inclusivo a espacios como plazas, parques, teatros, estadios, puentes, coliseos, aeropuertos, centros comerciales, entre otros, a fin de que se enriquezcan y propicien las intervenciones artísticas y creativas ${ }^{45}$. Además, la estrategia busca promover el desarrollo de productos de innovación tecnológica que faciliten el intercambio de los bienes y servicios culturales, como la fibra óptica, las antenas de radio, los satélites y los cables de cobre, y para llevar a cabo esta estrategia se pensó en líneas de crédito y cooperación a través de la Financiera del Desarrollo Territorial (FINDETER). Por otro lado, se establecieron los lineamientos

40 Congreso de la República de Colombia. Ley 1834, artículo 7..

41 Duque, Iván. Op. cit., p. 18.

42 Duque y Buitrago. Op. cit., pp. 169-175.

43 Congreso de la República de Colombia. Ley 1834, artículo 8.

44 Duque, Iván. Op. cit., p. 18.

45 Congreso de la República de Colombia. Ley 1834, artículo 5.․ 
de ciencia y tecnología de los Órganos Colegiados de Administración y Decisión (OCAD) para que desarrollen proyectos culturales de alto impacto a nivel regional y municipal ${ }^{46}$.

Por su parte, el artículo 13 de la Ley 1834 desarrolla la quinta estrategia denominada Integración, con base en los acuerdos comerciales suscritos por el país; con esta estrategia se busca facilitar la participación de las industrias creativas en actividades y mercados como co-nutrición, co-creación, co-producción, co-distribución, coprotección, co-inversión y co-consumo, de la mano del Ministerio de Comercio, Industria y Turismo, y mediante la consolidación de Mercados Integrados de Contenidos Originales (MICOs) ${ }^{47}$. La Integración conlleva el fortalecimiento de lazos internacionales que propicien el intercambio cultural y comercial, para que las industrias creativas nacionales puedan tener acceso al mercado mundial. En ese sentido, el Estado colombiano debe promover

... el desarrollo de las industrias creativas, con miras a que estas se conviertan en vehículos de integración y resocialización como generadoras de oportunidades laborales y económicas. En este sentido, se fortalecerán espacios de circulación independientes de todas las artes en general mediante el reconocimiento de los mismos espacios y equipamientos culturales ${ }^{48}$.

Con el párrafo anterior se motiva la sexta estrategia denominada Inclusión, la cual parte del entendido de que las actividades de la Economía Naranja no solo tienen la capacidad de generar empleos con una baja inversión, sino que ayudan a recuperar el tejido social, posibilitando la creación y el empoderamiento de identidades alternativas. La estrategia es un mecanismo con altas posibilidades de mitigar las brechas sociales que se suscitan en el país, acercando a la ciudadanía en un propósito común, la cultura ${ }^{49}$.

El reto del Estado para lograr las metas establecidas en esta estrategia es educar en economía creativa, y para ello, el artículo $100^{\circ}$ de la Ley Naranja señala que el Ministerio de Educación Nacional, en coordinación con el Servicio Nacional de Aprendizaje (sena) y el Ministerio de Cultura, basados en la Ley 115 de 1994, deben promover en las instituciones educativas la formación para el progreso cultural y creativo; de igual manera, el sena, la Dirección Nacional de Derecho de Autor (DNDA), o cualquier otra entidad administrativa a la que el Consejo Nacional de la Economía Naranja le asigne la función, realizarán jornadas de capacitación sobre economías creativas ${ }^{50}$.

La última estrategia de las $7 \mathrm{i}$ es la Inspiración, una estrategia que no sucede en el vacío, es decir, la sumatoria de innovación, imaginación, instrucción, incentivo,

48 Ibíd., artículo 5..

49 Ídem.

50 Congreso de la República de Colombia. Ley 1834, artículo 10.․ 
e individuo, dan como resultado la inspiración como valor fundamental dentro del proceso de creación ${ }^{51}$. En ese aspecto, para desarrollar las industrias creativas el gobierno colombiano se propone ampliar la inversión en Economía Naranja y en programas como Capital Semilla y Capital Emprendedor; igualmente, se propone crear mecanismos de financiación bajo la dirección del Banco de Desarrollo Empresarial y Comercio Exterior [Bancoldex ${ }^{52}$.

Como estrategia, la inspiración invita a trabajar por el cambio de visión social y empresarial, resaltando el talento, la innovación y la imaginación ${ }^{53}$. Tras esto, y de la mano de la estrategia anterior, es clave

... incluir y fortalecer los contenidos académicos con artes y otras disciplinas, que permitan desarrollar y complementar las ciencias básicas y las materias básicas con la creatividad, y ser un complemento para el desarrollo infantil y juvenil que derive en individuos sensibles, creativos, innovadores y emprendedores ${ }^{54}$.

Las 7i son las principales apuestas de la Ley 1834 de 2017 para fomentar las industrias creativas dentro de la economía en el país, estrategias que se desarrollan y se agrupan bajo las siguientes actividades:

\section{Tabla 3. ACtividades QUe agrupan las siete Estrategias}

\begin{tabular}{|c|c|c|c|c|c|c|}
\hline INSTITUCIONES & INFORMACIÓN & INSPIRACIÓN & INCLUSIÓN & INDUSTRIA & INTEGRACIÓN & INFRAESTRUCTURA \\
\hline $\begin{array}{l}\text { Creación Cor- } \\
\text { poración Co- } \\
\text { lombia Crea }\end{array}$ & $\begin{array}{l}\text { Sistema de in- } \\
\text { formación en } \\
\text { economía na- } \\
\text { ranja }\end{array}$ & $\begin{array}{l}\text { Fortalecimien- } \\
\text { to de escuelas } \\
\text { taller y talleres } \\
\text { escuelas }\end{array}$ & $\begin{array}{l}\text { Identificación } \\
\text { de brechas de } \\
\text { capacidades y } \\
\text { diseño de cua- } \\
\text { lificaciones }\end{array}$ & $\begin{array}{l}\text { Formación } \\
\text { para el empren- } \\
\text { dimiento }\end{array}$ & $\begin{array}{l}\text { Turismo cul- } \\
\text { tural }\end{array}$ & $\begin{array}{l}\text { Implementación de } \\
\text { mínimo cinco ADN }\end{array}$ \\
\hline $\begin{array}{l}\text { Ley de finan- } \\
\text { c i a m i e } \mathrm{n} \mathrm{to} \\
\text { (rentas naranja } \\
\text { exentas) }\end{array}$ & $\begin{array}{l}\text { Cuenta Satéli- } \\
\text { te de Cultura } \\
\text { y Economía } \\
\text { Naranja }\end{array}$ & $\begin{array}{l}\text { Programación } \\
\text { de estímulos y } \\
\text { concertación }\end{array}$ & $\begin{array}{l}\text { Transferencia } \\
\text { de conocimien- } \\
\text { to al interior de } \\
\text { los emprendi- } \\
\text { mientos crea- } \\
\text { tivos }\end{array}$ & $\begin{array}{l}\text { Laboratorio } \\
\text { de diseño de } \\
\text { artesanías de } \\
\text { Colombia }\end{array}$ & $\begin{array}{l}\text { Fortalecimien- } \\
\text { to de mercados } \\
\text { culturales y } \\
\text { creativos }\end{array}$ & $\begin{array}{l}\text { Línea de crédito Re- } \\
\text { activa - FINDETER } \\
\text { para infraestructura } \\
\text { cultural }\end{array}$ \\
\hline $\begin{array}{l}\text { FDC y amplia- } \\
\text { ción Ley } 1556\end{array}$ & $\begin{array}{l}\text { Mapeos regio- } \\
\text { nales y secto- } \\
\text { riales }\end{array}$ & $\begin{array}{l}\text { Espacio de ex- } \\
\text { perimentación } \\
\text { y laboratorios } \\
\text { creativos }\end{array}$ & $\begin{array}{l}\text { Competencias } \\
\text { creativas en la } \\
\text { infancia y la } \\
\text { juventud }\end{array}$ & $\begin{array}{l}\text { Fondo empren- } \\
\text { dedor (sENA) }\end{array}$ & $\begin{array}{l}\text { Fortaleci- } \\
\text { miento de la } \\
\text { participación } \\
\text { colombiana en } \\
\text { mercados ex- } \\
\text { tranjeros }\end{array}$ & $\begin{array}{l}\text { Regalías para proyec- } \\
\text { tos de infraestructura } \\
\text { cultural }\end{array}$ \\
\hline $\begin{array}{l}\text { Agendas re- } \\
\text { gionales para } \\
\text { la economía } \\
\text { creativa }\end{array}$ & $\begin{array}{l}\text { Red de obser- } \\
\text { vatorios }\end{array}$ & $\begin{array}{l}\text { Estímulo a la } \\
\text { investigación y } \\
\text { la creación }\end{array}$ & BEPS Naranja & $\begin{array}{l}\text { Programa INN- } \\
\text { pulsa }\end{array}$ & $\begin{array}{l}\text { Mercados in- } \\
\text { tegrados de } \\
\text { contenidos ori- } \\
\text { ginales }\end{array}$ & $\begin{array}{l}\text { Alianzas Público } \\
\text { Privadas (APP) para } \\
\text { construcción y ges- } \\
\text { tión de infraestruc- } \\
\text { tura }\end{array}$ \\
\hline
\end{tabular}

51 Duque, Iván. Op. cit., p. 10.

52 Congreso de la República de Colombia. Ley 1834, artículo 11.

53 Duque y Buitrago. Op. cit., pp. 187-192.

54 Duque, Iván. Op. cit., p. 20. 
ANÁLISIS DE LAS CARACTERÍSTICAS DE LA LEY I834 DE $20 I 7$ QUE FOMENTAN EL SECTOR CULTURAL EN COLOMBIA

\begin{tabular}{|c|c|c|c|c|c|c|}
\hline INSTITUCIONES & INFORMACIÓN & INSPIRACIÓN & INCLUSIÓN & INDUSTRIA & INTEGRACIÓN & INFRAESTRUCTURA \\
\hline \multirow{4}{*}{$\begin{array}{l}\text { PND: amplia- } \\
\text { ción de la Ley } \\
1556 \text { de } 2012 \\
\text { y extensión a } \\
\text { otros géneros } \\
\text { audiovisuales: } \\
\text { deducción de } \\
165 \% \text { en renta } \\
\text { para proyectos } \\
\text { de economía } \\
\text { creativa }\end{array}$} & & \multirow[t]{4}{*}{$\begin{array}{l}\text { Política de De- } \\
\text { recho de Autor }\end{array}$} & $\begin{array}{l}\text { Identificación } \\
\text { de brechas sec- } \\
\text { toriales }\end{array}$ & $\begin{array}{l}\text { Fábrica de pro- } \\
\text { ductividad }\end{array}$ & $\begin{array}{l}\text { Capacidades } \\
\text { empresariales } \\
\text { para elevar la } \\
\text { producción }\end{array}$ & \\
\hline & & & $\begin{array}{l}\text { Diseño de cua- } \\
\text { lificaciones }\end{array}$ & $\begin{array}{l}\text { Bonos Naranja } \\
\text { (Bancoldex) }\end{array}$ & $\begin{array}{l}\text { Sello Colombia } \\
\text { Crea }\end{array}$ & \multirow{3}{*}{$\begin{array}{l}\text { Estímulos a planes } \\
\text { de sostenibilidad de } \\
\text { infraestructuras cul- } \\
\text { turales }\end{array}$} \\
\hline & & & \multirow{2}{*}{$\begin{array}{l}\text { Piloto de for- } \\
\mathrm{m} \text { ación en } \\
\text { oficios audio- } \\
\text { visuales }\end{array}$} & & Pines Naranja & \\
\hline & & & & & $\begin{array}{l}\text { Estrategias de } \\
\text { comunicación }\end{array}$ & \\
\hline
\end{tabular}

Fuente: Ministerio de Cultura. “ABC Economía naranja”, s.f., p. 23.

De la mano de las 7i, el Gobierno Nacional decretó la promoción del sello "Creado en Colombia" impronta que promueve las industrias culturales y creativas del país a nivel nacional y alrededor del mundo, para que tengan un impacto positivo en la economía colombiana; este sello, coordinado por el Consejo Nacional de Economía Naranja y la Comisión Intersectorial de Propiedad Intelectual (CIPI), busca posicionar la identidad nacional por medio de la cultura y la creatividad ${ }^{55}$.

\section{CAPÍTULO 3. EL SECTOR CULTURAL EN LA LEY I834 DE 20 I7}

En la exposición de motivos Duque manifiesta que la de la Ley Naranja responde a las necesidades económicas de la economía creativa en el país y en el mercado internacional, compuesta por los sectores en los que el valor de los bienes y servicios se fundamentan en la "propiedad intelectual, el arte, la cultura, y otros sectores que clásicamente no son analizados desde la perspectiva de su impacto económico y las oportunidades que estos engloban" ${ }^{15}$. En un sentido amplio la economía creativa abarca en general el sector cultural y sus diversas actividades tales como "la arquitectura, las artes visuales y escénicas, las artesanías, el cine, el diseño, el editorial, la investigación y desarrollo, los juegos y juguetes, la moda, la música, la publicidad, el software, la televisión (TV), la radio y los videojuegos" 57 .

De acuerdo con lo expuesto por Duque, el Ministerio de Cultura ${ }^{58}$ elaboró una cartilla que sirve de herramienta para entender este modelo económico, demarcándolo del conjunto de actividades que han llegado a constituir un concepto más amplio que el de industrias creativas, al incluir no solo aquellas actividades que tradicionalmente se ubicaban en el campo de las políticas culturales, sino también otras actividades cuyos productos comparten las características de intangibilidad y el uso intenso del conocimiento en su proceso de producción. Es por esa distinción que se generaron tres clasificaciones de las actividades que conforman el modelo de desarrollo de la Ley Naranja.

55 Congreso de la República de Colombia. Ley 1834. Op. cit., artículo 14.

56 Duque, Iván. Op. cit., p. 6.

57 Ibíd., p.6

58 Ministerio de Cultura de Colombia. “ABC Economía Naranja”, s.f., p. 3. Disponible en [https://economianaranja.gov.co/sources/files/cartilla_economia_naranja.pdf]. 
Tabla 4. Actividades Que Conforman el modelo

de Desarrollo de la Ley Naranja

\begin{tabular}{|c|c|c|}
\hline \multirow[t]{4}{*}{ Artes y patrimonio } & Artes visuales & $\begin{array}{l}\text { Pintura, escultura, fotografía, video arte y perfor- } \\
\text { mance. }\end{array}$ \\
\hline & Artes escénicas & Conciertos, ópera, circo, orquesta, danza y teatro. \\
\hline & Turismo y patrimonio cultural & $\begin{array}{l}\text { Museos, cocinas tradicionales, artesanías, parques } \\
\text { naturales bibliotecas, archivos, festivales y carnavales. }\end{array}$ \\
\hline & Educación & Relacionadas con áreas culturales y creativas \\
\hline \multirow[t]{3}{*}{ Industrias culturales } & Editorial & Librerías, libros, periódicos, revistas y literatura. \\
\hline & Fonográfica & Música grabada. \\
\hline & Audiovisual & Cine, televisión, video y radio. \\
\hline \multirow[t]{3}{*}{$\begin{array}{l}\text { Creaciones funciona- } \\
\text { les, nuevos medios y } \\
\text { software de conteni- } \\
\text { dos }\end{array}$} & Medios digitales & $\begin{array}{l}\text { Videojuegos, contenidos interactivos audiovisuales, } \\
\text { plataformas digitales, creación de software, creación } \\
\text { de apps (código de programación) y animaciones. } \\
\text { Agencias de noticias y otros medios de información. }\end{array}$ \\
\hline & Diseño & $\begin{array}{l}\text { Interiores, artes gráficas e ilustración, joyería, ju- } \\
\text { guetes, industrial (producto), arquitectura, moda, } \\
\text { mobiliario. }\end{array}$ \\
\hline & Publicidad & $\begin{array}{l}\text { Servicios de asesoría, servicios creativos, producción } \\
\text { de material publicitario, utilización de medios de } \\
\text { difusión, creación, y realización de campañas de } \\
\text { publicidad, campañas de mercadeo y otros servicios } \\
\text { publicitarios. }\end{array}$ \\
\hline
\end{tabular}

Fuente: Ministerio de Cultura. “АвC Economía Naranja”, s.f., p. 3.

Sin embargo, dentro de los catorce artículos que componen la Ley 1834 de 2017, ley que se presenta como la política cultural para fomentar la economía creativa, no se expresa directamente el fomento del sector cultural, todo lo contrario, el desarrollo de la Ley Naranja se sustenta en las industrias creativas, su incentivo y su protección ${ }^{59}$.

Gäestan Tremblay ${ }^{60}$ define las industrias creativas como la evolución de los diversos sistemas de producción e intercambio de actividades culturales reguladas por un marco mercantil, y encaminadas a responder a los modelos de organización laboral capitalistas que operan mediante la separación entre productores y producto, creación y ejecución, es decir, que a través de estos modelos se pierde la relación entre el artista y el producto de su actividad u obra.

Se evidencia, entonces, que las llamadas industrias creativas adoptaron, como su nombre lo indica, un modelo de producción industrial facilitado por los avances tecnológicos que permiten aumentar la producción y circulación de productos y servicios a grandes escalas y distancias, logrando la expansión masiva de esos bienes, así como su comercialización nacional e internacional. A su vez, las industrias creativas gozan del fenómeno de la fusión organizacional, es decir, la creación y agrupación de grandes y poderosas organizaciones y personas, en su mayoría trans-

59 Congreso de la República de Colombia. Ley 1834, artículo 1..

60 Gäestan, Tremblay. Les industries de la culture et des communications au Québec et au Canada, Presses de l'Université du Quebec, 1990. 
nacionales, con capitales, incluso, más grandes que los presupuestos de muchos países latinoamericanos, lo que conlleva que se generen monopolios culturales ${ }^{61}$.

En ese sentido, las industrias creativas han venido especializando, avanzando y diversificando los procesos de producción industrial vinculados a la música, los libros, el cine o la radio, transformándose en grandes organizaciones que reportan altas utilidades, son importantes generadoras de empleo, promueven la inversión de capital y amplían los nichos de mercado culturales ${ }^{62}$.

Entre las categorías de las industrias creativas existen empresas o ideas innovadoras que antes no se consideraban posibles, innovación que surge como principal herramienta para la economía naranja y que es considerada como la mejor manera en que las empresas pueden crear valor, cambiando la forma en que se desarrollan los productos y servicios ${ }^{63}$.

En consecuencia, bajo las disposiciones de la Ley Naranja, en 2019 el Ministerio de Cultura ${ }^{64}$ publicó en su portal web un comunicado oficial en el que anunció la proyección de la inversión en ese sector de la economía, así como el balance en cifras de la inversión del Gobierno nacional en 2019 en proyectos en pro del desarrollo de la Política Naranja, a través de los cuales se apoyaron procesos de formación artística, emprendimiento cultural, circulación de bienes y servicios creativos y culturales, llevados a cabo mediante el trabajo articulado de 31 agencias del Estado, entre ellas el Consejo Nacional de Economía Naranja (CNEN). Al respecto, el viceministro de la Creatividad y la Economía Naranja, Felipe Buitrago, expresó que

... esta articulación del Gobierno Nacional ha permitido fortalecer la infraestructura cultural del país, abrir otras fuentes de financiamiento para impulsar el sector creativo, incrementar el número de emprendimientos culturales, aumentar las exportaciones de bienes y servicios culturales y creativos, apoyar proyectos de tecnología e innovación en industrias creativas, promover el turismo cultural y generar empleo para el sector ${ }^{65}$.

Sin embargo, a pesar del gran impacto económico que generan las industrias creativas, Germán Rey ${ }^{66}$ señala que son pocos los países en Latinoamérica que han explotado el desarrollo económico de las industrias culturales, en las redes de producción y distribución de ese tipo de bienes y servicios, en las cuales, participan creadores individuales, artistas, pequeñas y medianas empresas. El autor considera que, aunque se puede afirmar que las industrias creativas son promotoras y gene-

61 Rey. Op. cit., pp. 63-65.

62 Ibíd, p. 69.

63 Luzardo, Alejandra, De Jesús, Dyanis y Pérez, Michelle. "Economía Naranja: innovaciones que no sabías que eran de América Latina y el Caribe”, 2017, p. 65. Disponible en [https://publications.iadb.org/handle/11319/8330?\%20locale-attribute=es\&].

64 Ministerio de Cultura. "Más de 2 billones de pesos para la Economía Naranja en 2020", 2019. Disponible en [https://www.mincultura.gov.co/prensa/noticias/Paginas/M\%C3\%A1sde-2-billones-de-pesos-para-la-Econom\%C3\%ADa-Naranja-en-2020.aspx].

65 Ibíd.

66 Rey. Op. cit., p. 129. 
radoras de empleo para el sector cultural, al observar la economía creativa desde la perspectiva de las grandes organizaciones, "se puede generar la idea de que toda la dimensión económica pasa por esta infraestructura, generalmente poderosa, y que los productos culturales terminan siendo como cualquier mercancía que se tranza en el mercado"67.

Ahora bien, Rey ${ }^{68}$ plantea una discusión que se puede observar a partir de dos puntos de vista: i) las rentabilidades económicas que finalmente obtienen las grandes organizaciones, las industrias creativas, y ii) la dificultad de las pequeñas y medianas empresas culturales para competir en el mercado en unas condiciones de desventaja, la poca capacidad de generar empleo y el nivel de producción de bienes y servicios.

Por su parte, Gerald Raunig analiza los planteamientos que Max Horkheimer y Theodor W. Adorno plasmaron en un ensayo escrito a comienzos de los años cuarenta como crítica a la creciente influencia de las industrias del entretenimiento en Estados Unidos, y en el que expusieron cómo los actores de la industria cultural se lamentaban por no tener la posibilidad de convertirse fácilmente en empresarios; ahora, por el contrario, el problema es justamente que el empresario autónomo se ha convertido en una figura generalizada y crea, una tras otra, pequeñas empresas, con la etiqueta de industrias creativas, siendo esos pequeños negocios de productores y productoras de cultura autónomos en el campo de los nuevos medios de comunicación, la moda, el diseño gráfico, la cultura popular y, en el caso ideal, la acumulación de esas pequeñas empresas. "Mientras el modelo de institución de la industria cultural era la gran empresa establecida a largo plazo, las pseudoinstituciones de las industrias creativas se muestran como temporalmente limitadas, efímeras y basadas en proyectos" ${ }^{\prime \prime}$.

Es en este punto que las palabras del maestro en artes plásticas Germán Benjumea cobran mayor fuerza, al plantear la desigualdad de condiciones en la que se ven inmersos los creadores individuales, los artistas y las pequeñas y medianas empresas, frente a una Ley Naranja pensada para las grandes organizaciones.

El problema puede surgir cuando Puerto Candelaria, la Filarmónica de Medellín, el Ateneo Porfirio Barba Jacob, el Teatro Pablo Tobón Uribe, el centro de Desarrollo Cultural de Moravia, entre otras miles de propuestas están protegidas con la normatividad pensada para Netflix, Claro, Planeta, rcn, Conmebol, las ferias internacionales, Maluma, JBalvin, O, sea, la industria fonográfica y Google, pues las primeras requieren una legislación más específica para empresas culturales no lucrativas y no para la industria cultural y del entretenimiento ${ }^{70}$.

67 Ídem.

68 Ídem.

69 Gerald, Rauning. "La industria creativa como engaño de masas", 2018, p. 6. Disponible en [http://ayp.unia.es/r08/IMG/pdf/Laindustria-creativa.pdf].

70 Benjumea. Op. cit., p. 27. 
La inequidad de la normatividad se puede observar en el análisis que Jaramillo ${ }^{71}$ realiza sobre los beneficios tributarios que trae la Ley Naranja a la economía colombiana. Estos beneficios son considerados rentas tributarias exentas por un periodo de siete años para aquellos que desarrollen actividades de valor agregado tecnológico y creativo, siempre y cuando cumplan con los requisitos y disposiciones establecidas por el Decreto 286 de 2020, que implica necesariamente que los aspirantes tengan su domicilio en Colombia. Este beneficio va dirigido exclusivamente a sociedades constituidas antes del 31 de diciembre de 2021, las cuales deben generar, en un plazo máximo de tres años gravables, el monto mínimo de inversión de 4.400 UvT, igualmente, las sociedades deben cumplir con el monto mínimo de tres empleados relacionados directamente con las actividades creativas. De ese modo se descartan las pequeñas y medianas empresas que no generan los suficientes ingresos, y las empresas unipersonales, limitando, así, el acceso del sector cultural.

Por otro lado, dentro de las iniciativas del Gobierno Nacional por fomentar y cumplir con las estrategias de la Ley Naranja, se creó la línea de crédito denominada Exprimiendo la Naranja, financiada y soportada por Bancoldex para el crecimiento de la economía creativa en el país, dirigida exclusivamente al fortalecimiento de ese sector. La financiación presenta, aparentemente, tasas de interés muy bajas que garanticen el acceso de los pequeños empresarios siendo estas con base DTF, de " $7.19 \%$ hasta 3 años, $7.29 \%$ superiores a 3 y hasta 5 años, y $7.34 \%$ superior a 5 y hasta 7 años. [...] con base IBR $6.82 \%$ hasta 3 años, $6.92 \%$ superiores a 3 y hasta 5 años, y 6.97\% superior a 5 y hasta 7 años" (Cámara de Comercio de Bogotá, 2018). Aunque el sector cultural se puede llegar a beneficiar con esta destinación de recursos, existen grandes y evidentes limitaciones para acceder a ellos, toda vez que se requiere capacidad de endeudamiento y demostrar que existe un capital para asumir la deuda, aspecto que es lejano al sector toda vez que las empresas de la Economía Naranja, en gran parte, son emprendimientos o trabajadores informales, negocios en etapa de iniciación o simplemente una idea o proyecto, que no cuentan con garantías para respaldar sus obligaciones ante los bancos, razón por la cual los bancos los perciben como sujetos de crédito muy riesgosos y por lo general se abstienen de otorgarles financiaciones ${ }^{72}$.

Respecto del desarrollo de la Ley 1834 de 2017, basados en estos planes y proyectos para el aprovechamiento del potencial artístico y cultural de los colombianos, Diana Cifuentes, coordinadora misional del Observatorio de Cultura y Economía, señala que aunque la Ley Naranja "es una ley juiciosa que establece

71 Jaramillo, Andrea. "Incentivos tributarios para sociedades de Economía Naranja”, Philippi Prietocarrizosa Ferrero DU \& Uría, 2019. Disponible en [https://2019. vlex.com/\#search/jurisdiction:CO+content_type: $1+$ source: $12570 /$ andrea+jaramillo/WW/ $\mathrm{vid} / 773835201]$.

72 Camacho, Emanuel. “¿Es la 'Ley Naranja' la solución a los problemas de las industrias culturales y creativas?”, Expeditio, Fundación Universidad de Bogotá Jorge Tadeo Lozano, 2019. Disponible en [https://www.utadeo.edu.co/es/noticia/destacadas/ expeditio/264566/utadeo-es-regulacion-es-la-ley-naranja-la-solucion-los-problemas-de-lasindustrias-culturales-y]. 
una serie de beneficios en materia de financiación, así como alivios tributarios, aún falta superar varios cuellos de botella"73 en relación con la informalidad en el sector cultural y el verdadero acceso de las Pymes a los préstamos y bonos naranja. Estos cuellos de botella que menciona Cifuentes, van dirigidos al desconocimiento del sector financiero respecto de las dinámicas y necesidades del sector cultural, es decir, el valor económico de las actividades creativas, situación que en otros países se maneja con pleno conocimiento del ejercicio artístico y creativo donde

... los bancos hacen préstamos a estas empresas culturales bajo garantías sobre activos intangibles, es decir, la entidad bancaria financia, por ejemplo, sobre un guion de una producción cinematográfica. Esta situación no ocurre en Colombia, en la medida que los empresarios y emprendedores culturales deben disponer algunos de sus bienes tangibles, como una casa, para acceder a estos préstamos ${ }^{74}$.

Ese interés por plantear lineamientos económicos para las industrias creativas estuvo marcado por el protagonismo de los medios de comunicación y el comercio de bienes y servicios culturales, que abrieron nuevas posibilidades de circulación y comercialización, en los que predominaban el conocimiento, la creatividad y los nuevos medios digitales de comunicación ${ }^{75}$. Sin embargo, se debe entender y precisar que existe una economía creativa que pasa por diferentes procesos y manifestaciones socio-culturales, los cuales no solo implican el aspecto económico, sino también las dimensiones de identidad, tejido social, participación ciudadana y fortalecimiento de las tradiciones y lo institucional, con vínculos con las comunidades locales, los sectores sociales más vulnerables y las minorías ${ }^{76}$.

Respecto de las industrias creativas y culturales en América Latina y el Caribe, Luzardo, De Jesús y Pérez señalan que existe una clara comprensión de la importancia del vínculo emocional con el consumidor y su impacto en la sociedad. Si las ideas reúnen causas sociales que estimulan el consumo responsable tienen mayor acogida y aceptación; en ese sentido, los autores resaltan, por ejemplo, ideas que vinculan la preservación del medioambiente y la igualdad social, y sobre todo las empresas que "beneficien con justicia a todos los que conforman su cadena de valor" ${ }^{\prime 7}$.

Por lo anterior, las políticas culturales relacionadas con la economía creativa se deben pensar con un enfoque social que impacte más allá de lo económico, de la destinación de recursos, que realmente fomenten el sector cultural a través de la formalización del empleo para actividades creativas, que el Estado tenga una participación activa en el sector, al igual que la empresa privada y la ciudadanía,

77 Luzardo, De Jesús y Pérez. Op. cit., p. 32. 
y que, a la vez que incentivan la investigación, fortalezcan las instituciones administrativas del sector ${ }^{78}$.

Como ejemplo tenemos la caracterización que hicieron González y Botello ${ }^{79}$ de las prácticas artísticas en la ciudad de Cúcuta, estudio que puso en evidencia la existencia de prácticas empíricas, la mayor parte de ellas productos artísticos de baja calidad relacionados con la escasa oferta de programas de formación académica para la actividad artística, y con la falta de competencias y habilidades técnicas. A partir de ese estudio también se evidenció que en el sector cultural se presenta una mayor producción artística en las áreas musical y audiovisual. En general los autores concluyeron que los artistas desconocen la normatividad cultural y las políticas culturales, lo que limita su poder de innovación en cuanto a las técnicas, y crea la necesidad de desarrollar planes específicos para las áreas artísticas, y articularlos en procura de fortalecer los procesos investigativos, creativos, de circulación y formación, de forma que las instituciones, entidades y mecanismos de financiación de proyectos, den a conocer las estrategias o programas de estímulos existentes a nivel internacional, nacional, departamental y municipal que ayuden a disminuir las desigualdades y generen desarrollo cultural.

Vale la pena destacar que en su informe el Ministerio de Cultura ${ }^{80}$ precisa que en el desarrollo de la Economía Naranja conviven relaciones complejas entre las lógicas del mercado, los procesos de creación de bienes y servicios culturales, y las formas en que estos entran en circulación social. De ese modo, se generan dudas y respuestas confusas sobre el futuro de la relación entre la estandarización de la diversidad cultural, la imposición comercial de unos productos culturales específicos y la invisibilidad de otros, el predominio de algunas organizaciones y bienes, y la disminución de las manifestaciones culturales locales, tradicionales y minoritarias.

Por su parte, Carmen Inés Vásquez se refiere a los cuatro tipos de empresa que se deben fortalecer en la cadena de valor de la economía creativa. El primero son los emprendimientos consolidados, con más de tres años de funcionamiento, que tienen ventas continuas y modelos de negocio diversificados; explica que se trata de empresas emergentes que han logrado mantenerse, "tienen potencial de escalamiento a partir de nuevas fuentes de financiamiento, mejoramiento de rutas de circulación y el refuerzo de sus capacidades de trabajo" ${ }^{81}$. Al segundo tipo pertenecen las organizaciones comunitarias y sin ánimo de lucro, con grandes desafíos y débiles capacidades para su gestión; se definen como empresas asociativas, empren-

78 Benjumea. Op. cit., p. 28.

79 González, Neyla y Botello, Jorge. "Caracterización de la dimensión de las prácticas artísticas en el municipio de Cúcuta”, Universidad Libre de Colombia, 2019, p. 32. Disponible en [https://repository.unilibre.edu.co/bitstream/handle/10901/15460/ CARACTERIZACI\%C3\%93N\%20DE\%20LA\%20DIMENSI\%C3\%93N\%20DE\%20LAS\%20 PR\%C3\%81 CTICAS\%20ART\%C3\%8DSTICAS\%20EN\%20EL\%20MUNICIPIO\%20DE\%20 $\mathrm{C} \% \mathrm{C} 3 \% 9$ ACUTA.pdf? sequence $=1$ \&isAllowed $=\mathrm{y}]$.

80 Ministerio de Cultura. Op. cit., p. 22.

81 VÁsquez, Carmen. "Mincultura, eje de la Economía Naranja", Revista de la Contraloría General de la Nación, Economía colombiana, especial Economía Naranja, n. ${ }^{\circ}$ 354, s.f. p. 24. 
dimientos por necesidad o iniciativas personales y representan para el Ministerio de Cultura, entre otros, el reto de "potenciar valores más allá de lo económico; avanzar en el tema de derechos colectivos de autor; brindar herramientas para la sostenibilidad y diseñar estrategias que tengan en cuenta lo territorial" ${ }^{82}$. Un tercer tipo se relaciona con los emprendimientos emergentes, con potencial, pero con el desafío de mantenerse sobre todo financieramente; en este caso el Ministerio de Cultura entiende que "requieren cofinanciación, fortalecer sus capacidades y red de intermediarios para el desarrollo de sus mercados y la consolidación de su modelo de negocio" 83 . Por último se clasifican las grandes empresas con trayectoria, con peso en el mercado y capacidad financiera, empresas que pueden ser apoyo de inversión con potencial para la expansión de mercados y que aportan beneficios para el mejoramiento de infraestructuras físicas y digitales al servicio de la cultura. En consecuencia, la política integral de economía naranja que se comienza a desarrollar tiene como reto generar mecanismos diferenciales para cada uno de estos niveles.

\section{CONCLUSIONES}

La economía naranja se presentó en Colombia como una apuesta por la cultura y una estrategia a través de la cual el gobierno pretendía coordinar y articular lineamientos encaminados al fomento y mejora de los bienes y servicios culturales dentro de la economía nacional, y para ello era necesario realizar un estudio y establecer una conceptualización óptima para su regulación; sin embargo, lo que inicialmente se evidenció en la presente investigación fue que definir el sector cultural genera controversias respecto de sus delimitaciones, y también contraposiciones en los discursos sobre el campo de acción de la cultura y de la industria creativa, lo que a su vez repercute en su valor, por lo que se trata de una delimitación necesaria de mercado que imposibilita que efectivamente se trabaje sobre las necesidades propias del sector.

En ese sentido, queda claro que la Ley 1834 de 2017 no hace ninguna distinción entre sector cultural, empresa e industria creativa, distinción que, al no estar inmersa en la ley, genera desventajas competitivas entre los entes que hacen parte de dicho sector.

Por otro lado, la intención del Gobierno era resaltar la importancia de la cultura en la economía, definiendo políticas culturales encaminadas a la industrialización y el crecimiento de la producción nacional con el fin de democratizar el acceso a la cultura. Esa revalorización de las manifestaciones culturales implica para la política pública concordar derechos humanos, fundamentales y colectivos respecto de la creación, la expresión, el acceso y el consumo cultural; sin embargo, se observa que dentro de los catorce artículos que componen la Ley 1834 de 2017, ley para 
el fomento de las economías creativas, no se establece directamente el fomento del sector cultural, sino que más bien el desarrollo de la Ley Naranja se fundamenta en las industrias creativas, su incentivo y su protección, siendo así una normatividad que se enfoca en lo comercial y no en lo cultural.

De acuerdo con el planteamiento de la economía naranja, las industrias creativas son promotoras y generadoras de empleo y oportunidades para el sector cultural, pero al estudiar a fondo la economía creativa desde la perspectiva de las grandes organizaciones se observa que toda la dimensión cultural-económica pasa por una estructura industrial, y que los productos culturales terminan siendo una mercancía que se comercializa en el mercado, perdiéndose la relación entre el artista y el producto de su actividad u obra. En ese sentido, se entiende que la Ley Naranja está pensada para las grandes organizaciones, su capacidad de generar empleo, adquirir y generar recursos, y la producción y distribución de bienes y servicios culturales, enfoque que resultaría contrario al entorno en el cual se desenvuelven los agentes de la Economía Naranja que, en gran parte, son emprendimientos o trabajadores informales, negocios en etapa de iniciación o simplemente ideas o proyectos.

Por su parte, las estrategias de la Ley 1834 de 2017 buscan integrar a los procesos económicos ideas, contenidos, bienes y servicios culturales alrededor de un proyecto económicamente sostenible, y para ello se debe superar la brecha que supone para los artistas el desconocimiento de la normatividad cultural y de las políticas culturales, con el fin de no limitar el poder de innovación, y lograr una articulación que fortalezca los procesos investigativos, creativos, de circulación y formación, que mejore las prácticas de las industrias creativas, a fin de generar mayores y mejores oportunidades, que de a conocer las instituciones, entidades y mecanismos públicos de financiación de proyectos, estrategias o programas de estímulos existentes a nivel internacional, nacional, departamental y municipal que ayuden a disminuir las desigualdades y generen desarrollo cultural. Es un gran desafío para el Gobierno demostrarle al sector cultural que esta política de Economía Naranja no busca mercantilizar la cultura y a la vez tomar las medidas necesarias para fortalecer los canales de comunicación y fomento de esas políticas, con el fin de que las empresas e industrias creativas aprovechen el rubro aportado por el gobierno para el crecimiento y desarrollo del sector cultural.

En síntesis, son las dinámicas económicas del mercado nacional e internacional de las industrias creativas las que determinan el acceso a la cultura, y la forma como se debe manifestar la producción y la distribución de los bienes y servicios culturales, los contenidos y los mecanismos de distribución, condicionando al sector cultural a los intereses y las necesidades de las industrias. En cualquier caso, es necesario que la política desarrollada para el fomento de la Economía Naranja esté alineada con las exigencias de un ecosistema del que hacen parte todos los actores del sector. De la forma como se aborden los retos de la Economía Naranja depende la sostenibilidad de la industria y su éxito como nuevo pilar de desarrollo del país. 


\section{REFERENCIAS}

Aguado, Luís Fernando. Configuración y delimitación de la economía de la cultura: elementos históricos, analíticos y metodológicos, Universidad de Sevilla, 2010.

Álvarez, Miguel Ángel. Industrias creativas y culturales y la economía de la imaginación, Ábaco, 2010.

Arroyo, Luís Miguel. "Sectores de la cultura", Observatorio Cultural del Proyecto Atalaya. Manual Atalaya, apoyo a la gestión cultural, 2014. Disponible en [http://atalayagestioncultural.es/capitulo/sectores-cultura].

Benjumea, Germán. "Economía cultural en Medellín", Diverciudad, n. ${ }^{\circ} 23$, 2018.

Camacho, Emanuel. “¿Es la 'Ley Naranja' la solución a los problemas de las industrias culturales y creativas?”, Expeditio, Fundación Universidad de Bogotá Jorge Tadeo Lozano, 2019. Disponible en [https://www.utadeo.edu.co/es/ noticia/destacadas/expeditio/264566/utadeo-es-regulacion-es-la-ley-naranjala-solucion-los-problemas-de-las-industrias-culturales-y].

Congreso de la República de Colombia. Ley 1834. "Por medio de la cual se fomenta la economía creativa Ley Naranja”, Diario Oficial n. ${ }^{\circ} 50.242$ del 23 de mayo de 2017.

Congreso de la República de Colombia. Ley 397. "Por la cual se desarrollan los artículos 70, 71 y 72 y demás artículos concordantes de la Constitución Política y se dictan normas sobre patrimonio cultural, fomentos y estímulos a la cultura, se crea el Ministerio de la Cultura y se trasladan algunas dependencias", Diario Oficial n. 43102 del 7 de agosto de 1997.

Constitución Política de Colombia. 1991. Gaceta Constitucional n. ${ }^{\circ} 116$ de 20 de julio de 1991.

Contraloría General de la Nación. Economía Colombiana. Revista de la Contraloría General de la República, año 33, n. ${ }^{\circ} 354$, s.f.

Del Corral, Milagros. "Hacia nuevas políticas de desarrollo de las industrias culturales", Anuario Industrias Culturales, Observatorio de Industrias Culturales de la Ciudad de Buenos Aires, 2006. Disponible en [http://www.ub.edu/cultural/wp-content/uploads/2019/12/1-1_1316768187_bgc13-MCorral.pdf].

Duque, Iván y Buitrago, Felipe. La economía naranja: una oportunidad infinita, Banco Interamericano de Desarrollo, 2013.

Duque, Iván. Proyecto de Ley 104 de 2015, Exposición de motivos, 2015. Disponible en [http://leyes.senado.gov.co/proyectos/index.php/textos-radicados-senado/26-textos-radicados/pl-radicados-2015-2016/533-proyecto-deley-104-de-2015].

Escobar, Gabriela, Forero, Tatiana y Vargas, Paula. "La institucionalidad de la economía naranja en Colombia: un estudio neo-institucional para el periodo 2010-2014", 2017. Disponible en [https://ciencia.lasalle.edu.co/ negocios_relaciones/43]. 
Gäestan, Tremblay. Les industries de la culture et des communications au Québec et au Canada, Presses de l'Université du Quebec, 1990.

Gerald, Rauning. "La industria creativa como engaño de masas", 2018. Disponible en [http://ayp.unia.es/r08/ImG/pdf/Laindustria-creativa.pdf].

González, Neyla y Botello, Jorge. "Caracterización de la dimensión de las prácticas artísticas en el municipio de Cúcuta”, Universidad Libre de Colombia, 2019. Disponible en [https://repository.unilibre.edu.co/ bitstream/handle/10901/15460/CARACTERIZACI\%C3\%93N\%20DE\%20 LA\%2ODIMENSI\%C3\%93N\%20DE\%2OLAS\%20PR\%C3\%81CTICAS\%2O ART \% C $3 \% 8$ DSTICAS \% 20 EN \% 20 EL \% 2 OMUNICIPIO \% 2 ODE \% 20 $\mathrm{C} \% \mathrm{C} 3 \% 9$ ACUTA.pdf?sequence $=1$ \&isAllowed $=\mathrm{y}]$.

Gutiérrez, Diana. Economía naranja y oportunidades de negocio, Fundación Universitaria del Área Andina, 2018.

Herrero, Luis. "La contribución de la cultura y las artes al desarrollo económico regional", Investigaciones Regionales, 2011.

Howkins, John. "The Creative Economy: How People Make Money from Ideas", UK, Penguin, 2001. Disponible en [https://bookports.com/show/the-creativeeconomy-how-people-make-money-from-.html].

Jaramillo, Andrea. "Incentivos tributarios para sociedades de economía naranja”, Philippi Prietocarrizosa Ferrero DU \& Uría. Núm, 2019. Disponible en [https://2019.vlex.com/\#search/jurisdiction:CO+content_ type:1+source:12570/andrea+jaramillo/WW/vid/773835201].

Luzardo, Alejandra, De Jesús, Dyanis y Pérez, Michelle. "Economía naranja: innovaciones que no sabías que eran de América Latina y el Caribe", 2017. Disponible en [https://publications.iadb.org/handle/11319/8330?\%20 locale-attribute $=e s \&]$.

Ministerio de Cultura. "Compendio de Políticas Culturales", 2010. Disponible en [https://www.mincultura.gov.co/areas/fomento-regional/Documents/ Compendio-Pol\%C3\%ADticas-Culturales.pdf].

Ministerio de Cultura. "ABC Economía naranja”, s.f. Disponible en [https:// economianaranja.gov.co/sources/files/cartilla_economia_naranja.pdf].

Ministerio de Cultura. "Más de 2 billones de pesos para la Economía Naranja en 2020", 2019. Disponible en [https://www.mincultura.gov.co/prensa/noticias/ Paginas/M\%C3\%A1s-de-2-billones-de-pesos-para-la-Econom\%C3\%ADaNaranja-en-2020.aspx].

Ministerio de Cultura. "Compendio de Políticas Culturales", 2010. Disponible en [https://www.mincultura.gov.co/areas/fomento-regional/Documents/ Compendio-Pol\%C3\%ADticas-Culturales.pdf].

Ministerio de Cultura. "Impacto económico de las industrias culturales en Colombia”, Equipo Central de Economía y Cultura del Convenio Andrés Bello, Colección Economía y Cultura, 2003. 
Ochoa, Ana María. Entre los deseos y los derechos: un ensayo crítico sobre políticas culturales, Bogotá, Instituto Colombiano de Antropología e Historia (ICANH), 2003.

Quintana, Boris. El color naranja del diseño, CEIDE, 2018.

Rey, Germán. Industrias culturales, creatividad y desarrollo, Madrid, Agencia Española de Cooperación Internacional para el Desarrollo, s.f.

ReY, Germán. "Las políticas culturales en Colombia: la progresiva transformación de sus comprensiones", Ministerio de Cultura de Colombia, Compendio de Políticas Culturales, 2010. Disponible en [https://www.mincultura.gov. co/areas/fomento-regional/Documents/Compendio-Pol\%C3\%ADticasCulturales.pdf].

UNCTAD. Economía creativa Informe 2010. "Economía creativa: una opción factible de desarrollo", Naciones Unidas, 2010.

VÁsquez, Carmen. "Mincultura, eje de la economía naranja", Revista de la Contraloria General de la Nación. Economía colombiana, especial Economía Naranja, n. ${ }^{\circ} 354$, s.f. 